\title{
Evolução Regional da Produtividade da Mão-de-Obra na Agropecuária Gaúcha: uma Aplicação da Matriz de Markov
}

Valter José Stulp ${ }^{1}$

Resumo - O estudo analisa a convergência regional dos níveis de produtividade da mão de obra na agropecuária do Rio Grande do Sul, através de uma matriz de Markov. Examina, também, as variáveis explicativas desta convergência, através da técnica estatística dos componentes principais seguida de regressão estatística. Os dados são provenientes dos censos agropecuários do Instituto Brasileiro de Geografia e Estatística (IBGE) dos anos 1975 e 1995/96. O estudo considera quatro classes de níveis de produtividade da mão de obra. As regiões da classe superior, contendo os grandes estabelecimentos rurais, com criação de gado, tendem a migrar, no longo prazo, para as classes inferiores. A causa parece ser a redução da área explorada por unidade de mão de obra. A classe mais baixa tende a manter, aproximadamente, o mesmo percentual de regiões que não evoluem na produtividade, talvez porque os estabelecimentos são pequenos para a mecanização, não direcionam o sistema de produção para produtos de maior valor agregado e não adotam mudanças tecnológicas.

Palavras-chave: convergência regional, produtividade da mão de obra, agropecuária do Rio Grande do Sul.

\footnotetext{
${ }^{1}$ Prof. do Departamento de Ciências Econômicas - Faculdade de Administração, Contabilidade e Economia -PUCRS. O artigo contou com a colaboração da FAPERGS que concedeu uma bolsa de iniciação científica

E-mail: stulp@zaz.com.br
} 
Evolução Regional da Produtividade da Mão-de-Obra na Agropecuária Gaúcha: uma Aplicação da Matriz de Markov

Abstract. This study analyses the regional convergence of the levels of labor productivity in the agricultural sector of the state of Rio Grande do Sul, through a Markov matrix. It also examines the variables that explain this convergence, through the statistical technique of principal components followed by statistical regression. The study is based on the data from Agricultural Censuses of the Instituto Brasileiro de Geografia e Estatistica (IBGE) referring to the years of 1975 and 1995/96.

The study considers four classes of levels of labor productivity. The regions in the upper class, containing the large cattle raising farms, show a tendency to migrate, in the long run, to the lower classes. The reason seems to be the reduction in the area of land available per unit of labor. The lower class tends to maintain, in the long run, approximately the same percentage of the total regions, which will not evolve in the level of labor productivity, maybe because the farms are too small to get mechanized, or do not change the production system to products that aggregate more value, or do not adopt technological innovations.

Key Words: regional convergence, labor productivity, agricultural sector of Rio Grande do Sul.

Jel Classification: J01 e R23

\section{1 - Introdução}

A população rural do Rio Grande do Sul vem diminuindo nas últimas décadas. As taxas geométricas de redução anual foram 2,09\%, 1,49\% e 1,51\%, respectivamente nas décadas de 1970, 1980 e 1990. (IBGE, 2002).

Assim, para a agropecuária do Estado cumprir as suas funções, como a oferta crescente de alimentos para consumo doméstico, ampliação do mercado para os produtos da indústria, expansão da oferta da poupança, geração de divisas externas, etc., dado o declínio de sua mão de obra, é imprescindível aumentar a produtividade deste fator. Isto é necessário também para aumentar a renda dos trabalhadores que permanecem neste setor, reduzindo os incentivos para a migração rural-urbana.

Gasques e Conceição (2001) concluíram que se a produtividade da 
mão de obra na agricultura do Rio Grande do Sul em 1970 é expressa pelo índice 100, o índice referente ao ano 1995 será igual a 193, representando um aumento de $2,66 \%$ ao ano.

Stülp e Binz (2002), com base nos censos agropecuários do IBGE de 1985 e 1995/96, concluíram que a mão de obra ocupada no setor agropecuário do Estado diminuiu $21 \%$ neste período, mas que a sua produtividade - medida em termos de valor agregado da produção por equivalente-homem - aumentou em todos os tamanhos de estabelecimentos rurais.

Embora se tenha constatado um aumento da produtividade na agropecuária gaúcha em anos recentes, permanecem duas questões a serem respondidas. A primeira é se há uma tendência de convergência, entre as várias regiões do Estado, para um nível único de produtividade mais elevado. A segunda é que variáveis explicariam a mudança de uma região no seu nível de produtividade da mão de obra.

O primeiro tipo de questão, ou seja, se os países ou regiões com diferentes níveis de renda ou produtividade dos fatores alcançariam no futuro um mesmo patamar, preferencialmente o daqueles situados no topo da classificação, tem sido um dos enfoques da pesquisa econômica (Baumol, 1986; Barro e Sala-i-Martin, 1991, 1992).

Diversos estudos também abordam a questão das variáveis associadas à produtividade da mão de obra no setor agropecuário.

Assim, Stülp, Marquetti e Fochezatto (2002) verificaram que na agropecuária do Rio Grande do Sul, além dos recursos terra e capital, a assistência técnica e o tipo de cultura explorada influenciam a produtividade da mão de obra.

Watkins (apud Albuquerque e Nicol, 1987) afirma que o crescimento no setor agropecuário seria gerado pela produção e exportação de uma mercadoria principal que determinaria a procura pela mão de obra, influenciando a sua produtividade.

Fialho e Maia (1983) examinando os dados do censo agropecuário do IBGE de 1975, verificaram que no estado de São Paulo a produtividade média da mão de obra era maior nas propriedades rurais grandes em comparação com as pequenas. Estas propriedades utilizariam processos de produção intensivos em equipamentos mecânicos poupadores de mão de obra. 
No Rio Grande do Sul, da mesma forma que em outros Estados brasileiros, há diversidade regional na estrutura agrária, nos tipos de culturas e criações (com produtos de exportação, destinados à industrialização ou à alimentação direta), nas características dos solos quanto à fertilidade, textura, profundidade e topografia, na velocidade de adoção de novas tecnologias, da mecanização, etc. Portanto, diversas foram as variações na produtividade regional da mão de obra empregada na agropecuária gaúcha ao longo do tempo.

É a convergência regional ou não nos níveis de produtividade da mão de obra do setor agropecuário gaúcho que se analisa neste estudo. Examinam-se, também, variáveis associadas às mudanças nestes níveis de produtividade. Os resultados da análise poderão orientar medidas políticas apropriadas a um maior dinamismo do setor rural.

\section{2 - Metodologia}

Esta análise é feita com base em dados dos censos agropecuários do Instituto Brasileiro de Geografia e Estatística (IBGE) dos anos de 1975 e 1995/96.

Há vários métodos para analisar se ocorre convergência entre regiões ou países quanto aos níveis de uma variável como PIB per capita, produtividade de um fator, etc.

Assim, tem-se o método que utiliza o conceito de $\beta$-convergência. Neste, testa-se a hipótese de que a taxa de crescimento da variável, em uma região, é tanto menor quanto mais elevado for o seu nível, na mesma, no início do período. Outro método utiliza o conceito de $\sigma$ convergência (convergência sigma), que se refere à redução da dispersão dos valores da variável ao longo do tempo (Barro e Sala-i-Martin, 1995).

Estes métodos de análise da convergência entre regiões, acima mencionados, estão sujeitos a críticas. Existe a possibilidade de inconsistência entre os conceitos $\beta$ e $\sigma$ - convergência (Friedman, 1992 e Quah, 1993). Além disto, eles não mostram a evolução das regiões entre os vários níveis na direção da distribuição final.

O método de matriz de Markov, utilizado neste estudo, permite não só analisar se está havendo convergência entre as regiões, mas também 
a sua dinâmica em termos do número de regiões que se encontram nos vários níveis ao longo do tempo, assim como o tempo necessário para alcançar o equilíbrio final.

Para analisar a evolução regional da produtividade da mão de obra na agropecuária do Rio Grande do Sul, com base nos anos de 1975 e 1995, considera-se o Estado dividido em regiões geograficamente idênticas ao longo das últimas décadas, ou seja, cada região abrangendo a mesma área geográfica ao longo do período da análise. Devido ao grande número de emancipações municipais ocorridas nas últimas décadas era necessário, em muitos casos, agregar um grande número de municípios para obter uma região idêntica ao longo deste período.

Este estudo utiliza a divisão regional do Estado considerada em dois estudos de Stulp (2003) e que abrangiam o período de 1960 a 1995 . O número de regiões que permanecem geograficamente idênticas no Estado desde 1960 até 1995 é 75 (vide quadro 1 no anexo).

A produtividade da mão de obra, em cada região, é o valor agregado da produção agropecuária dividido pela mão de obra. Ela é entendida como uma produtividade média.

O valor agregado da produção agropecuária é igual ao valor da produção, mais a variação no valor do estoque do rebanho, sendo descontadas as despesas. As despesas são os gastos com adubos, corretivos, agrotóxicos, sal, rações industriais e medicamentos para animais, transportes, combustíveis, energia elétrica, etc. Não são descontadas as despesas com salários pagos, quota-parte da produção, pagamento de arrendamento, de empreitadas e impostos. A variação no estoque do rebanho é igual ao valor dos animais nascidos, mais o dos comprados e menos o dos vitimados, dos vendidos e dos abatidos.

A mão de obra é medida em equivalentes-homens. Os Censos Agropecuários apresentam a mão de obra ocupada nos estabelecimentos rurais classificada em várias categorias, por sexo e uma divisão por idade. Para a transformação da mão de obra em equivalentes-homens utiliza-se a tabela apresentada por Guerreiro (1996).

A produtividade da mão de obra de cada região é expressa em valor relativo à média calculada sobre todas as regiões, a qual é considerada igual a 1,00. Este procedimento é realizado em relação a cada um dos dois anos, 1975 e 1995/96. (vide tabela 3 do anexo). 
Há, assim, para cada um dos dois anos, uma função de distribuição regional da produtividade que possibilita a classificação das regiões em classes. Pela organização das duas distribuições em uma mesma estrutura de classes, examina-se a migração das regiões de uma classe para outra de 1975 a 1995.

Para determinar a estrutura de classes é necessário estabelecer a dimensão do intervalo das classes. Esta dimensão é importante, pois um valor muito grande faz com que haja muitas observações em cada intervalo, diminuindo a variância da estimativa. No entanto o formato do histograma não é adequado, o que leva a aumentar o viés da estimativa. Uma dimensão pequena reduz o viés da estimativa, mas aumenta a sua variância (Pagan e Ullah, 1999).

Esta dimensão deve ser escolhida de modo a resultar em um ótimo trade-off entre viés e variância da estimativa. Devroye e Györfi (apud Magrini, 1999, p.264) concluem que, quando a distribuição é normal, o valor ótimo do intervalo de classe seria dado por $h=2,72 \mathrm{sn}^{-1 / 3}$ sendo $\mathrm{h}$ a dimensão do intervalo, s o desvio-padrão da distribuição e n o número de observações. Mas, segundo Magrini (1999, p.264) este valor de $\mathrm{h}$ seria adequado mesmo se as observações não seguissem uma distribuição normal. Portanto esta é a expressão utilizada neste estudo para a estimativa do intervalo de classe.

Testa-se a normalidade de cada distribuição de produtividade, a de 1975 e a de 1995/96, através do teste de Kolmogorov-Smirnov. Neste teste compara-se a distribuição de freqüência acumulada observada, com a acumulada teórica esperada na hipótese de normalidade. O valor absoluto da diferença máxima entre as freqüências acumuladas das duas distribuições constitui o valor D para este teste (Siegel, 1956).

A partir das duas distribuições de produtividade, a de 1975 e de 1995/ 96, determina-se uma matriz $M$ de probabilidades de transição das regiões entre as classes, denominada matriz de Markov. Esta matriz origina um sistema de equações de diferenças, $F_{t+1}=M^{*} F_{t}$ em que $F_{t}$ é a distribuição regional da produtividade no tempo t e $\mathrm{F}_{\mathrm{t}+1}$ é a do tempo $\mathrm{t}+1$. A solução do sistema informa se as regiões convergem, no longo prazo, em termos de produtividade da mão de obra, e qual a velocidade desta convergência. 
A hipótese básica associada a este procedimento é que as probabilidades de transição sejam estacionárias, isto é, que a probabilidade de passagem de uma classe para outra seja invariável com o tempo.

Além da análise da convergência ou não das regiões, se estuda, também, que variáveis poderiam explicá-la. A variável explicada é a diferença entre a produtividade relativa de cada região, em relação à média, no ano de 1995/96 e a sua produtividade relativa em 1975. As regiões que progrediram apresentam diferenças positivas e as que regrediram têm diferenças negativas.

A análise poderia ser realizada através da regressão estatística da variável explicada sobre o conjunto das variáveis explicativas se não fosse por dois tipos de problemas. Um é o grande número de variáveis explicativas em relação ao de observações e o outro a alta correlação estatística entre várias variáveis explicativas. Assim, antes da regressão estatística reduz-se o número de variáveis originais, agregando-as em combinações lineares, não correlacionadas entre si, denominadas componentes principais. Após, regressa-se a variável explicada sobre estes componentes principais (Stevens, 1996, cap.11). O procedimento estatístico utiliza o programa "Statistical Package for Social Sciences" (SPSS).

Cada variável original é associada ao componente principal com o qual a sua carga ou correlação for maior. A carga é a correlação de Pearson entre a variável original e o componente principal também denominado fator.

\section{3 - Resultados}

O valor de $D$ do teste de normalidade de Kolmogorov-Smirnov é igual a 0,207 para a distribuição do ano de 1975 e 0,167 para a do ano de 1995/96. O valor limite que consta na Tabela E (Siegel, 1956, p.251) para 75 observações a $1 \%$ de significância estatística é 0,188 . Portanto, em relação à distribuição de 1975 se rejeita a hipótese de que ela seja normal, mas não se rejeita a mesma em relação à distribuição de 1995/ 96, ao nível de significância de $1 \%$.

Apesar de a distribuição de 1975 não ser uma distribuição normal, se utiliza a fórmula $\mathrm{h}=2,72 \mathrm{sn}^{-1 / 3}$ para calcular a dimensão $\mathrm{h}$ do intervalo de classe, baseado na observação de Magrini (1999, p.264) de que este 
valor de h seria adequado, mesmo se as observações não seguissem uma distribuição normal.

Os valores de h obtidos são 0,481 para a distribuição de 1975 e 0,439 para a de 1995/96. Considera-se o valor médio de 0,460 estabelecendose quatro classes comuns às duas distribuições, as quais englobam regiões com valores relativos: a) abaixo de 0,54 ; b) entre 0,54 até 1,00 ; c) acima de 1,00 até 1,46; d) e acima de 1,46.

Utilizando os dados da Tabela 3 (no anexo) e com base nestas quatro classes, obtém-se a matriz de transição de Markov e o seguinte sistema de equações de diferenças:

$$
\left[\begin{array}{l}
F 1_{t+1} \\
F 2_{t+1} \\
F 3_{t+1} \\
F 4_{t+1}
\end{array}\right]=\left[\begin{array}{cccc}
4 / 12 & 11 / 41 & 0 & 0 \\
5 / 12 & 27 / 41 & 2 / 10 & 1 / 12 \\
3 / 12 & 3 / 41 & 8 / 10 & 2 / 12 \\
0 & 0 & 0 & 9 / 12
\end{array}\right]\left[\begin{array}{l}
F 1_{t} \\
F 2_{t} \\
F 3_{t} \\
F 4_{t}
\end{array}\right]
$$

A distribuição inicial (a de 1975) das 75 regiões entre as quatro classes é a seguinte:

$\mathrm{F} 1_{0}=12 / 75=0,16 ; \mathrm{F}_{0}=41 / 75=0,547 ; \mathrm{F} 3_{0}=10 / 75=0,133$ e F4 ${ }_{0}=12 / 75=0,16$.

Com base nesta distribuição inicial a solução do sistema de equações é: ${ }^{2}$

$$
\left[\begin{array}{l}
F 1_{t} \\
F 2_{t} \\
F 3_{t} \\
F 4_{t}
\end{array}\right]=\left[\begin{array}{cccc}
0,18 & -0,08 & 0,15 & -0,08 \\
0,44 & -0,12 & 0,17 & 0,06 \\
0,38 & 0,04 & -0,32 & 0,03 \\
0 & 0,16 & 0 & 0
\end{array}\right]\left[\begin{array}{c}
(1)^{t} \\
(0,75)^{t} \\
(0,65)^{t} \\
(0,15)^{t}
\end{array}\right]
$$

A solução de equilíbrio de longo prazo é dada por:

$\mathrm{F} 1_{\mathrm{t}}=0,18 ; \mathrm{F} 2_{\mathrm{t}}=0,44 ; \mathrm{F} 3_{\mathrm{t}}=0,38 ; \mathrm{F} 4_{\mathrm{t}}=0$.

Constata-se que, no longo prazo, desaparecerá a classe de produtividade mais elevada. A classe de produtividade mais baixa conterá 18\% das regiões, ficando próxima dos iniciais 16\%. A segunda classe baixará dos iniciais $54,7 \%$ para $44 \%$ e a terceira aumentará dos iniciais $13,3 \%$ para abranger $38 \%$ do total das regiões. A tendência é, portanto, uma 
parcela das regiões da segunda classe e as regiões da quarta classe migrarem para a terceira classe.

A segunda raiz característica, em valor absoluto, fornece uma medida da velocidade com que este equilíbrio de longo prazo é alcançado. Essa velocidade é entendida como o tempo necessário para percorrer a metade da distância entre a posição inicial e a de equilíbrio de longo prazo $(d m)$. Ela é dada por $d m=-\log 2 / \log |0,75|=2,409$ períodos.

Multiplicando-se 2,409 períodos por 20,5 anos, que é o número de anos de um período (de julho de 1975 a dezembro de 1995), obtém-se o tempo necessário, 49 anos, para o setor agropecuário percorrer a metade da distância entre a posição inicial e a de equilíbrio de longo prazo.

A próxima questão que merece uma análise são os fatores associados às migrações das regiões entre classes de produtividade da mão de obra. Com base nesta informação se pode inferir sobre os tipos de regiões que tenderiam a migrar de uma classe para outra.

Como variáveis explicativas seleciona-se um conjunto de 21 variáveis. As informações sobre os valores das mesmas são obtidas dos censos agropecuários de 1975 e 1995/96. Estes valores são referentes às 75 regiões. Estas variáveis são, com a respectiva simbologia que é utilizada na tabela abaixo, as que seguem.

1) Variação percentual entre 1975 e 1995/96 no número de estabelecimentos rurais:
a) de menos de 20 hectares. (vpnemvi);
b) de 20 a menos de 200 hectares (vpneved);
c) de mais de 200 hectares(vpnemad);

2) Aumento, em pontos percentuais, de 1975 a 1995/96, na participação da área de cada cultura na área de lavoura temporária total. No caso da uva é a participação na área de lavoura permanente total.
a) arroz (aarearr);
b) feijão (aarefe);
c) fumo (aarefu);
d) trigo (aaretr);
e) soja (aareso);
f) milho (aaremi);
g) uva (aareuv)

\footnotetext{
${ }^{2}$ Ver Simon e Blume (1994) cap.23
} 
3) Aumento, em pontos percentuais, de 1975 a 1995/96, na participação do valor total da produção agropecuária de:

a) animais de grande porte (aprangpo);

b) animais de médio porte (apranmpo);

c) aves e pequenos animais (apraves);

d) lavouras permanentes (aprlavp);

e) lavouras temporárias (aprlavt).

4) Variação percentual, de 1975 a 1995/96, nos:

a) cavalos vapor de trator (vpcv);

b) mão de obra ocupada (vpeh).

5) Percentual de estabelecimentos rurais da região que em 1995/96:

a) usaram adubo (pestadu);

b) usaram calcário ou outro corretivo (pestcal);

c) o produtor informou ter usado assistência técnica (pestass);

d) o produtor é associado a alguma cooperativa (pestcoo).

Destas 21 variáveis são extraídos sete fatores ou componentes principais (tabela 1). As cargas maiores das variáveis explicativas associadas a cada fator são apresentadas em negrito. Os sete fatores explicam $73,14 \%$ da variância total destas 21 variáveis. Na regressão das diferenças entre as produtividades relativas das regiões nos dois anos sobre estes sete fatores, apenas os quatro primeiros se mostram estatisticamente significantes (Tabela 2).

O primeiro fator é constituído pelas variáveis: aumento percentual do número de estabelecimentos de menos de 20 hectares, dos de menos de 200 hectares, dos equivalentes-homens, e da redução na participação da área de trigo na área de lavoura. Na regressão o sinal do coeficiente do primeiro fator é negativo. Assim a conclusão relacionada a este primeiro fator é que as regiões em que ocorrem aumentos no percentual de estabelecimentos com menos de 200 hectares e aumentos na mão de obra ocupada têm tendência de convergirem para as classes de produtividade mais baixa da mão de obra. As regiões com aumento na participação da área de trigo na área de lavoura temporária total tendem a convergir para as classes de produtividade mais alta.

O segundo fator, estatisticamente significante na regressão, apresenta o coeficiente com sinal positivo. As variáveis que compõem este 
Tabela 1 - Matriz dos componentes principais: variáveis e respectivas cargas.

\begin{tabular}{|l|l|l|l|l|l|l|l|}
\hline \multirow{2}{*}{ Variáveis } & \multicolumn{7}{|c|}{ Cargas dos componentes principais } \\
\hline & 1 & 2 & 3 & 4 & 5 & 6 & 7 \\
\hline Vpnemvi & $\mathbf{0 , 8 6 0}$ & $8,902 \mathrm{E}-02$ & $-6,491 \mathrm{E}-02$ & 0,138 & $3,316 \mathrm{E}-02$ & $6,331 \mathrm{E}-02$ & $-0,132$ \\
\hline Vpeh & $\mathbf{0 , 8 4 9}$ & $6,022 \mathrm{E}-02$ & $-7,746 \mathrm{E}-02$ & $9,796 \mathrm{E}-03$ & $-7,478 \mathrm{E}-02$ & $9,293 \mathrm{E}-02$ & $2,401 \mathrm{E}-02$ \\
\hline Vpneved & $\mathbf{0 , 8 3 0}$ & $-0,121$ & $-4,060 \mathrm{E}-02$ & $1,843 \mathrm{E}-02$ & $4,343 \mathrm{E}-02$ & $-7,956 \mathrm{E}-03$ & 0,212 \\
\hline Aaretr & $\mathbf{- 0 , 4 6 5}$ & $2,422 \mathrm{E}-02$ & $-0,311$ & $7,776 \mathrm{E}-02$ & $9,253 \mathrm{E}-03$ & 0,381 & $-0,193$ \\
\hline Pestcal & $8,356 \mathrm{E}-02$ & $\mathbf{0 , 8 9 6}$ & $-3,034 \mathrm{E}-02$ & 0,143 & $2,583 \mathrm{E}-02$ & $-5,202 \mathrm{E}-02$ & $-8,177 \mathrm{E}-02$ \\
\hline Pestadu & $-8,136 \mathrm{E}-02$ & $\mathbf{0 , 8 3 1}$ & $5,268 \mathrm{E}-02$ & 0,170 & 0,169 & 0,134 & 0,173 \\
\hline apranmpo & $-0,180$ & $\mathbf{0 , 5 4 1}$ & $9,931 \mathrm{E}-02$ & $-0,528$ & 0,447 & $-3,046 \mathrm{E}-02$ & $8,445 \mathrm{E}-02$ \\
\hline pestass & $9,219 \mathrm{E}-02$ & $\mathbf{0 , 5 3 7}$ & 0,278 & 0,507 & $-0,163$ & 0,146 & $-4,127 \mathrm{E}-02$ \\
\hline aprangpo & $-0,158$ & $-6,448 \mathrm{E}-02$ & $\mathbf{0 , 8 4 0}$ & $-0,253$ & $9,541 \mathrm{E}-02$ & $2,149 \mathrm{E}-02$ & $-2,866 \mathrm{E}-02$ \\
\hline aprlavp & 0,153 & $-7,288 \mathrm{E}-02$ & $-\mathbf{0 , 7 8 2}$ & $-0,118$ & 0,216 & $-8,473 \mathrm{E}-02$ & $-1,793 \mathrm{E}-02$ \\
\hline aareso & $-0,235$ & $-0,124$ & $\mathbf{- 0 , 6 1 6}$ & $-0,253$ & $-0,106$ & $-0,415$ & $1,285 \mathrm{E}-02$ \\
\hline pestcoo & 0,428 & $1,059 \mathrm{E}-02$ & $\mathbf{0 , 5 5 7}$ & 0,197 & 0,107 & $-0,454$ & $8,040 \mathrm{E}-02$ \\
\hline apraves & $-2,027 \mathrm{E}-02$ & 0,101 & $8,583 \mathrm{E}-02$ & $\mathbf{0 , 7 8 4}$ & 0,255 & $5,144 \mathrm{E}-02$ & 0,276 \\
\hline vpcv & $9,514 \mathrm{E}-02$ & 0,276 & $-7,040 \mathrm{E}-02$ & $\mathbf{0 , 7 8 3}$ & 0,154 & $-7,299 \mathrm{E}-02$ & $3,012 \mathrm{E}-02$ \\
\hline aarefe & 0,186 & $-0,159$ & $-9,571 \mathrm{E}-02$ & $2,302 \mathrm{E}-02$ & $\mathbf{0 , 7 3 4}$ & $9,795 \mathrm{E}-02$ & $-0,379$ \\
\hline aprlavt & 0,177 & $-0,248$ & $-0,225$ & $-0,265$ & $-\mathbf{0 , 7 3 0}$ & $8,748 \mathrm{E}-02$ & $-0,309$ \\
\hline aarearr & $8,074 \mathrm{E}-03$ & $-0,406$ & 0,208 & $-0,239$ & $-\mathbf{0 , 6 1 0}$ & 0,130 & $-0,174$ \\
\hline aarefu & 0,265 & 0,343 & 0,129 & $5,846 \mathrm{E}-02$ & $5,259 \mathrm{E}-03$ & $\mathbf{0 , 7 4 9}$ & $-9,386 \mathrm{E}-02$ \\
\hline aareuv & $-0,114$ & $-0,379$ & 0,204 & $-9,634 \mathrm{E}-02$ & $-0,124$ & $\mathbf{0 , 6 0 5}$ & 0,228 \\
\hline vpnemad & 0,169 & $5,452 \mathrm{E}-02$ & $4,149 \mathrm{E}-04$ & 0,152 & $-1,211 \mathrm{E}-03$ & $-0,145$ & $\mathbf{0 , 7 4 2}$ \\
\hline aaremi & $2,044 \mathrm{E}-03$ & $-3,043 \mathrm{E}-02$ & $-1,637 \mathrm{E}-02$ & $4,301 \mathrm{E}-02$ & $5,258 \mathrm{E}-02$ & 0,446 & $\mathbf{0 , 6 2 2}$ \\
\hline
\end{tabular}

Fonte: Censos Agropecuários do Rio Grande do Sul de 1975 e 1995/96- IBGE

Tabela 2 - Resultados da regressão das diferenças nas produtividades relativas da mão de obra das regiões sobre os fatores

\begin{tabular}{|l|l|l|}
\hline Estatísticas e fatores & Valores e coeficientes & Significância estatística \\
\hline $\mathrm{R}^{2}$ ajustado & 0,323 & \\
\hline $\mathrm{F}$ & 6,053 & 0,000 \\
\hline Constante & $-2,698 \mathrm{E}-17$ & 1,000 \\
\hline Fator 1 & $-7,422 \mathrm{E}-02$ & 0,055 \\
\hline Fator 2 & 0,161 & 0,000 \\
\hline Fator 3 & $-0,135$ & 0,001 \\
\hline Fator 4 & $7,764 \mathrm{E}-02$ & 0,045 \\
\hline Fator 5 & $4,969 \mathrm{E}-02$ & 0,195 \\
\hline Fator 6 & $-1,064 \mathrm{E}-02$ & 0,780 \\
\hline Fator 7 & $5,405 \mathrm{E}-02$ & 0,159 \\
\hline
\end{tabular}

Fonte: Censos Agropecuários do Rio Grande do Sul de 1975 e 1995/96- IBGE 
Evolução Regional da Produtividade da Mão-de-Obra na Agropecuária Gaúcha: uma Aplicação da Matriz de Markov

fator são, todas com sinal positivo, o percentual de estabelecimentos na região que em 1995/96 aplicaram calcário, adubo, tinham assistência técnica e apresentaram grande aumento entre 1975 e 1995/96 na participação dos animais de médio porte no valor total da produção agropecuária.

Assim, a persistir a tendência observada de 1975 a 1995/96, as regiões com alto percentual de estabelecimentos rurais tecnicamente assistidos, utilizando adubos e corretivos de solo e se dedicando à criação de animais de médio porte, aumentariam o seu nível de produtividade da mão de obra.

O terceiro fator, estatisticamente significante na regressão, é constituído pelas variáveis aumento da participação do valor dos animais de grande porte no valor total da produção agropecuária e o percentual de estabelecimentos associados a cooperativas em 1995/96. Estas variáveis apresentam sinais positivos. Portanto, como o coeficiente do fator é negativo na regressão, conclui-se que as regiões com criação de animais de grande porte tenderiam a convergir para classes mais baixas de produtividade da mão de obra. A variável percentual de estabelecimentos associados a cooperativas estaria indicando que as regiões com grande número de associados também tenderiam a decair nos seus níveis de produtividade da mão de obra. Porém, isto talvez se explique pela sua correlação com o aumento da participação do valor dos animais de grande porte no valor total da produção agropecuária, cujo coeficiente é de 0,30 e já que ambas as variáveis estão no mesmo fator.

Outras duas variáveis que integram o terceiro fator são os aumentos, entre 1975 a 1995/96, da participação da área de soja na área de lavoura temporária e da participação do valor das lavouras permanentes no valor total da produção agropecuária. Estas variáveis apresentam sinais negativos, o que, em conjunto com o sinal negativo do coeficiente do fator na regressão, indicaria que regiões que expandissem a área de soja e a de culturas permanentes tenderiam para classes mais elevadas de produtividade.

O quarto fator, estatisticamente significante na regressão, indica que as regiões que apresentam aumentos da participação do valor de aves e pequenos animais no valor total da produção agropecuária e da meca- 
nização agrícola em termos de número de cavalos vapor de trator tenderiam para níveis mais elevados de produtividade.

Embora, reconhecendo que a produtividade da mão de obra é apenas um indicador parcial, o trabalho analisa, diretamente, apenas a produtividade deste fator. Ele não analisa a produtividade total dos fatores e nem a produtividade da terra. O motivo desta decisão são as considerações feitas nos parágrafos iniciais do artigo onde se afirma que a mão de obra do setor rural do Rio Grande do Sul está em declínio. Assim, para a agropecuária do Estado continuar cumprindo as suas funções de oferta da mesma quantidade de alimentos, de produtos de exportação, etc., é necessário que a produtividade deste fator aumente.

Porém, o estudo analisa a relação entre a variação na produtividade da mão de obra e na da terra. Assim, consideram-se os dois componentes da produtividade do trabalho (VA/EH) que são a produtividade da terra (VA/A) e a relação terra/homem (A/EH), de modo que VA/EH = VA/A*A/EH (Gasques e Conceição, 2001, p.46). Nesta relação VA é o valor agregado da produção agropecuária, EH é o número de unidades de mão de obra e A é a área de terra explorada. Em relação a cada produtividade e à relação terra/homem, consideram-se as variações de 1975 a 1995/96 nos valores de cada região, expressos em termos relativos à média do Estado. Verificou-se que o coeficiente de correlação de Pearson entre as variações na produtividade da mão de obra e as variações na produtividade da terra é igual a 0,505 e estatisticamente significante a $1 \%$. O coeficiente de correlação entre as variações na produtividade da mão de obra e as variações na relação terra/homem é igual a 0,508 e estatisticamente significante a $1 \%$.

O sinal positivo do primeiro coeficiente de correlação mostra que, em muitas regiões, a convergência quanto à produtividade da terra segue no mesmo sentido da convergência em relação à produtividade da mão de obra. Esta seria a situação das regiões em que ocorre a adoção concomitante da tecnologia química, biológica e mecânica, resultando no aumento da produtividade de ambos os fatores. A adoção dos dois tipos de tecnologia ocorreu nas regiões produtoras de soja e trigo e nas produtoras de arroz irrigado.

A correlação positiva entre a variação na produtividade da mão de 
obra e a relação terra/homem indica que quando a área disponível por unidade de mão de obra diminui, a produtividade deste fator decresce.

\section{4 - Conclusões}

Com base na evolução histórica da produtividade da mão de obra na agropecuária das regiões do Rio Grande do Sul ocorrida no período que vai do censo agropecuário de 1975 ao censo de 1995/96, verifica-se que a classe de nível de produtividade mais alta tende a migrar, no futuro, para as classes de níveis mais baixos e a de nível mais baixo tende a se manter estável com aproximadamente o mesmo percentual de regiões. Haverá uma redução na participação relativa das regiões na segunda classe e um aumento acentuado na participação na terceira classe.

As explicações para as migrações das regiões entre classes de produtividade da mão de obra podem ser classificadas em três categorias. Uma está relacionada com a substituição entre os fatores de produção que ocorre ao longo do tempo. As outras duas explicações são a mudança na estrutura de produção e o avanço tecnológico.

Ao se considerar uma função de produção em que o produto é o valor agregado da produção agropecuária e os fatores são a mão de obra, a terra e o capital (representado pelos tratores) verificou-se que, para um mesmo nível de produção (uma isoquanta no espaço tridimensional), o aumento das pessoas ocupadas por unidade de área, ou seja, a substituição da terra por mão de obra, reduz a produtividade deste último fator. Porém, a substituição da mão de obra por tratores aumenta a sua produtividade. São estes dois tipos de substituições que estão ocorrendo na agropecuária do Estado.

Assim, verifica-se que as regiões em que ocorrerem aumentos no percentual de estabelecimentos com menos de 200 hectares e aumentos na mão de obra ocupada terão tendência de convergirem para as classes de produtividade mais baixa da mão de obra. Ao longo do tempo existe a tendência dos grandes estabelecimentos se fragmentarem, por herança, reforma agrária, etc. e a região absorver mais mão de obra. Há, assim, a geração de mais emprego, mas, se o volume de produção regional não aumentar, haverá a redução da produtividade da mão de 
obra. É esta a tendência observada entre 1975 e 1995/96 em muitas regiões de grandes estabelecimentos criadores de gado.

Por outro lado, observa-se que as regiões que apresentam aumentos na mecanização agrícola em termos de número de cavalos vapor de trator tenderiam para níveis mais elevados de produtividade da mão de obra. Há a substituição do homem pela máquina. Em muitas regiões este aumento na mecanização, observado no período de 1975 a 1995/ 96, estava associado com a expansão das lavouras de trigo e soja que tiveram efeito positivo sobre a produtividade da mão de obra.

Outra explicação para as migrações das regiões entre classes de níveis de produtividade da mão de obra está nas mudanças na estrutura de produção. Através da migração para produtos de maior valor agregado, haveria um deslocamento da isoquanta, expressa em termos de valor da produção, em direção à origem dos eixos, aumentando a produtividade dos fatores de produção, pois seriam necessárias menores quantidades de fatores para o mesmo valor de produção. Isto pode ter ocorrido nas regiões que passaram do cultivo de lavouras temporárias para as frutíferas como maçã, uva e a produção de vinho, dos animais de grande porte para os de médio e pequeno porte (suínos e aves), etc., aumentando o valor total da produção por unidade de mão de obra e de terra, sem ter havido mudança nos preços.

O avanço tecnológico, ao deslocar a função de produção, também pode elevar a produtividade da mão de obra. É o que se constata com a tecnologia divulgada pela assistência técnica e associada à utilização de adubos e calcário, variáveis associadas positivamente a maior produtividade.

Assim, parece que no Estado do Rio Grande do Sul as regiões de grandes estabelecimentos rurais, devido à mudança na estrutura agrária, tenderiam a baixar da quarta classe para uma classe inferior de produtividade da mão de obra ao longo do tempo. Para evitar esta queda haveria necessidade de que mudanças na estrutura agrária fossem acompanhadas pela introdução de sistemas de produção com maior valor agregado por unidade de mão de obra, através de mudanças na estrutura de produção e na tecnologia.

As regiões com estabelecimentos rurais menores, mas que conseguem mudar a sua estrutura de produção para produtos de maior va- 
- Evolução Regional da Produtividade da Mão-de-Obra na Agropecuária Gaúcha: uma Aplicação da Matriz de Markov

lor agregado, que atingem maior volume de produção através de mudança tecnológica, ou ainda, em que a mecanização provoca a emigração da mão de obra, poderiam subir de classe de produtividade da mão de obra.

Haveria, porém, um conjunto de regiões de pequenos estabelecimentos, com produtos de pouco valor agregado, baixos níveis tecnológicos e grandes quantidades de mão de obra, que tendem a permanecer na classe de produtividade mais baixa.

\section{5 - Referências Bibliográficas}

Albuquerque M. C. C. de e Nicol R. Economia Agrícola. McGraw - Hill. São Paulo. 1987

Barro R.J. e Sala-i-Martin, X. Convergence across States and Regions. Brookings Papers on Economic Activity, 1991, p.107-182.

Barro R.J. e Sala-i-Martin, X. Convergence. Journal of Political Economy. 100, 1992, p.223-251.

Barro R.J. e Sala-i-Martin, X. Economic Growth Theory, MIT Press, 1995.

Baumol W.J. Productivity growth, convergence, and welfare: what the long-run data show, American Economic Review, 54, 1986, p.10721085 .

Fialho I. P. M.e Maia M. M. Tamanho da Propriedade e Eficiência na Agricultura Paulista: o que os Censos Mostram. Revista de Economia e Sociologia Rural. SOBER. Brasília. 1983.

Friedman M. Do old fallacies ever die? Journal of Economic Literature, 30, 1992, p.2129-132.

Gasques J. G. e Conceição J. C. P. R. Transformações Estruturais da Agricultura e Produtividade Total dos Fatores. In: Transformações da Agricultura e Políticas Públicas. IPEA. Brasília. 2001. 
Guerreiro E. Produtividade do Trabalho e da Terra na Agropecuária Paranaense. Revista de Economia e Sociologia Rural. SOBER. Brasília. 1996.

IBGE Censo Agropecuário 1995-1996.-№ 22 - Rio Grande do Sul. Rio de Janeiro. 1998.

IBGE Censo Agropecuário 1975.-Vol I Tomo 20 - Rio Grande do Sul. Rio de Janeiro. 1979.

IBGE (2002) -Site: http://www.sidra.ibge.gov.br/ (acessado em 10/ 05/2002).

Le Gallo, J. Space-time analysis of GDP disparities among European regions: A Markov chains approach. Dijon/França: University of Burgundy, Março 2001.

Magrini, S. The evolution of income disparities among the regions of the European Union. Regional Science and Urban Economics, № 29, 1999.

Pagan, A.; Ullah, A. Nonparametric Econometrics. Cambridge/UK: Cambridge University Press, 1999.

Quah D. Galton's fallacy and tests of the convergence hypothesis, Scandinavian Journal of Economics, 95, 1993, p.427-443.

Siegel, S. Nonparametric Statistics for the Behavioral Sciences. Nova Iorque: McGraw-Hill Book Company, 1956.

Simon, C.P. e Blume, L. Mathematics for Economists. Nova Iorque: W.W. Norton \& Company Inc., 1994.

Stevens, J. Applied Multivariate Statistics for the Social Sciences. Lawrence Erlbaum Associates, Publishers. Mahwah. Nova Jersey. 1996. 
Stülp V. J., Marquetti A. e Fochezatto A. Produtividade da Mão de Obra na Agropecuária do Rio Grande do Sul. 1ํEcontro de Economia Gaúcha. FEE/PUCRS. 2002.

Stülp V. J.e Binz L. A. Análise comparativa da agropecuária gaúcha entre duas épocas: 1985 e 1995/96. Revista Redes. Vol. 7 Fascículo 3 EDUNISC - Santa Cruz do Sul 2002..

Stülp V. J. Crescimento Agrícola no Rio Grande do Sul de 1960 a 1996. In: Terceras Jornadas de Historia Economica. Montevidéu. Uruguai. 2003.

Stülp V. J. Fatores Associados à Redução da População Rural do Rio Grande do Sul. In: XLI Congresso Brasileiro de Economia e Sociologia Rural. Juiz de Fora. MG. 2003.

Recebido em novembro de 2003 e revisto em abril de 2004. 


\section{Anexos}

Tabela 3 - Produtividade da mão de obra ocupada no setor agropecuário nas regiões do Rio Grande do Sul nos anos de 1975 e 1995/96. Valores relativos à média das regiões, em cada ano, considerada igual à unidade

\begin{tabular}{|c|c|c|c|c|c|c|c|c|}
\hline \multirow{2}{*}{ Regiões } & \multicolumn{2}{|c}{ Anos } & Regiões & \multicolumn{3}{|c|}{ Anos } & Regiões & \multicolumn{2}{|c|}{ Anos } \\
\cline { 2 - 3 } & 1975 & $95 / 96$ & - & 1975 & $95 / 96$ & & 1975 & $95 / 96$ \\
\hline 1 & 0,6762 & 0,9040 & 2 & 0,6861 & 0,7555 & 3 & 1,3488 & 1,0195 \\
4 & 1,6958 & 2,2760 & 5 & 0,6184 & 0,5416 & 6 & 0,6298 & 0,5537 \\
7 & 1,1468 & 1,1505 & 8 & 0,6220 & 0,4588 & 9 & 1,3937 & 1,2094 \\
10 & 1,6207 & 1,3687 & 11 & 0,8556 & 0,5780 & 12 & 0,8682 & 0,5133 \\
13 & 1,0412 & 1,0371 & 14 & 0,8760 & 0,8764 & 15 & 0,5568 & 0,6512 \\
16 & 0,4613 & 1,2686 & 17 & 0,5725 & 0,6473 & 18 & 0,6211 & 0,9253 \\
19 & 0,5288 & 0,5240 & 20 & 0,5828 & 0,7121 & 21 & 0,6830 & 0,9165 \\
22 & 0,4146 & 1,2613 & 23 & 0,6445 & 0,7589 & 24 & 0,5277 & 0,8071 \\
25 & 0,4181 & 0,6318 & 26 & 0,6295 & 0,4983 & 27 & 0,4864 & 0,4692 \\
28 & 0,6091 & 0,6727 & 29 & 0,7204 & 0,8691 & 30 & 0,9563 & 1,0713 \\
31 & 0,5406 & 0,5393 & 32 & 0,4705 & 0,5227 & 33 & 0,6349 & 0,2967 \\
34 & 1,6853 & 1,7137 & 35 & 0,8844 & 0,5322 & 36 & 0,5227 & 0,9130 \\
37 & 1,7452 & 1,6224 & 38 & 0,5905 & 0,4973 & 39 & 0,7532 & 0,9826 \\
40 & 0,4463 & 0,8059 & 41 & 0,4054 & 1,1290 & 42 & 0,6930 & 0,7972 \\
43 & 0,5153 & 0,7078 & 44 & 0,6126 & 0,8745 & 45 & 0,7998 & 1,0138 \\
46 & 1,0063 & 1,2674 & 47 & 0,6204 & 1,3461 & 48 & 0,6589 & 0,5097 \\
49 & 0,7422 & 0,4386 & 50 & 0,6430 & 0,5956 & 51 & 0,5692 & 0,5484 \\
52 & 0,7729 & 0,7412 & 53 & 0,7502 & 0,7436 & 54 & 0,6575 & 0,6366 \\
55 & 2,3353 & 3,5986 & 56 & 0,8453 & 0,6504 & 57 & 1,9351 & 2,7547 \\
58 & 1,1370 & 1,1335 & 59 & 4,0371 & 3,2150 & 60 & 0,4088 & 0,3306 \\
61 & 0,8298 & 0,7481 & 62 & 0,7416 & 0,7040 & 63 & 0,7352 & 0,7263 \\
64 & 0,6176 & 0,4183 & 65 & 0,6388 & 0,9090 & 66 & 0,6206 & 0,3915 \\
67 & 1,3482 & 1,0290 & 68 & 1,3420 & 0,9403 & 69 & 1,0997 & 0,8471 \\
70 & 2,9624 & 2,2169 & 71 & 1,5917 & 0,6279 & 72 & 3,3053 & 3,0495 \\
73 & 2,0476 & 1,0162 & 74 & 1,3356 & 1,0823 & 75 & 3,8727 & 2,9079 \\
\hline
\end{tabular}

Fonte: estimativas baseadas nos censos agropecuários do IBGE dos anos de 1975 e 1995/96 referentes ao Rio Grande do Sul. 
Quadro 1 - Regiões do Estado do Rio Grande do Sul que são geograficamente idênticas de 1960 a 1996*.

(continua)

\begin{tabular}{|l|l|}
\hline Regiões & Municípios existentes na região em 1996. \\
\hline Região 1 & Agudo \\
\hline Região 2 & Dona Francisca. Faxinal do Soturno. São José do Polésine. \\
\hline Região 3 & Restinga Seca. \\
\hline Região 4 & Cacequi. \\
\hline Região 5 & Jaguari. Nova Esperança do Sul, \\
\hline Região 6 & Mata \\
\hline Região 7 & Santa Maria. Silveira Martins. São Martinho da Serra. São Gabriel \\
\hline Região 8 & São Pedro do Sul \\
\hline Região 9 & $\begin{array}{l}\text { São Sepé. Formigueiro. Vila Nova do Sul. São Vicente do Sul } \\
\text { Região 10 }\end{array}$ \\
\hline Região 11 & Júlio de Castilhos. Ivorá. Pinhal Grande. Nova Palma. Quevedos. \\
\hline Região 12 & Santiago. \\
\hline Região 13 & Cachoeira do Sul. Cerro Branco. Paraíso do Sul. \\
\hline Região 14 & Rio Pardo. Pântano Grande. Passo do Sobrado. \\
\hline Região 15 & $\begin{array}{l}\text { Arroio do Meio. Nova Bréscia. Encantado. Anta Gorda. Ilópolis. } \\
\text { Putinga. Capitão. Pouso Novo. Relvado. Travesseiro. }\end{array}$ \\
\hline Região 16 & Bom Retiro do Sul. \\
\hline Região 17 & $\begin{array}{l}\text { Lajeado. Cruzeiro do Sul. Boqueirão do Leão. Venâncio Aires. } \\
\text { Santa Cruz do Sul. Soledade. Barros Cassal. Fontoura Xavier. } \\
\text { Progresso. Santa Clara do Sul. Sério. Gramado Xavier. Mato } \\
\text { Leitão. Sinimbu. Vale do Sol. Ibirapuitã. Lagoão. Mormaço. Tunas. } \\
\text { São José do Herval }\end{array}$ \\
\hline Região 24 & Gramado \\
\hline Região 25 & Rolante. Riozinho. \\
\hline Região 18 & Muçum \\
\hline Região 19 & Taquari. Paverama. \\
\hline Região 20 & Candelária \\
\hline Região 21 & Vera Cruz \\
\hline Região 22 & Canela \\
\hline Região 23 & $\begin{array}{l}\text { Dois Irmãos. Ivoti. Estância Velha. Lindolfo Collor. Morro Reuter. } \\
\text { Nova Petrópolis. Picada Café. Santa Maria do Herval. Presidente }\end{array}$ \\
\hline
\end{tabular}




\begin{tabular}{|l|l|}
\hline Região 26 & Taquara. Igrejinha. Parobé. Sapiranga. Nova Hartz \\
\hline Região 27 & Três Coroas \\
\hline Região 28 & Feliz. Alto Feliz. Vale Real. Linha Nova \\
\hline Região 29 & $\begin{array}{l}\text { São Sebastião do Caí. Portão. Canoas. São Leopoldo. Sapucaia do } \\
\text { Sul. Bom Princípio. Montenegro. Salvador do Sul. Barão. Carlos } \\
\text { Barbosa. São Vendelino. Tupandi. Brochier. Capela de Santana. } \\
\text { Harmonia. Maratá. Pareci Novo. Poço das Antas. São José do } \\
\end{array}$ \\
$\begin{array}{l}\text { Hortêncio. São Pedro da Serra. Nova Santa Rita. Caxias do Sul. } \\
\text { São Marcos. Farroupilha. Bento Gonçalves. Monte Belo do Sul. } \\
\text { Santa Tereza. Estrela. Teutônia. Colinas. Roca Sales. Imigrante. } \\
\text { Garibaldi. }\end{array}$ \\
\hline Região 30 & $\begin{array}{l}\text { Osório. Tramandaí. Capão da Canoa. Palmares do Sul. Viamão. } \\
\text { Alvorada. São José do Norte. Mostardas. Tavares. Cidreira. Imbé. } \\
\text { Maquine. Terra de Areia. Xangri-lá. }\end{array}$ \\
\hline Região 31 & Santo Antônio da Patrulha \\
\hline Região 32 & $\begin{array}{l}\text { Torres. Arroio do Sal. Morrinhos do Sul. Três Cachoeiras. } \\
\text { Três Forquilhas. }\end{array}$ \\
\hline Região 33 & Campo Bom \\
\hline Região 34 & Esteio \\
\hline Região 35 & Gravataí. Cachoeirinha. Glorinha. \\
\hline Região 36 & Novo Hamburgo \\
\hline Região 37 & Porto Alegre \\
\hline Região 38 & General Câmara \\
\hline Região 39 & Triunfo \\
\hline Região 40 & Antônio Prado. Nova Roma do Sul \\
\hline Região 41 & Flores da Cunha. Nova Pádua \\
\hline Região 42 & Veranópolis. Cotiporã. Fagundes Varela. Vila Flores \\
\hline Região 43 & Arvorezinha. Itapuca. Nova Alvorada \\
\hline Região 44 & $\begin{array}{l}\text { Nova Prata. Nova Araçá. Nova Bassano. Parai. Guabijú. } \\
\text { Protásio Alves. São Jorge. Vista Alegre do Prata. }\end{array}$ \\
\hline Região 45 & Bom Jesus. São José dos Ausentes \\
\hline Região 46 & São Francisco de Paula. Cambará do Sul. Jaquirana. \\
\hline Região 47 & Vacaria. Esmeralda. Campestre da Serra. Ipê. \\
\hline Região 48 & $\begin{array}{l}\text { Cerro Largo. Porto Xavier. Roque Gonzáles. São Paulo das } \\
\text { Missões. Salvador das Missões. São Pedro do Butiá. }\end{array}$ \\
\hline Região 49 & Guarani das Missões. \\
\hline Gaurama. Áurea. Centenário. \\
\hline
\end{tabular}


Evolução Regional da Produtividade da Mão-de-Obra na Agropecuária Gaúcha: uma Aplicação da Matriz de Markov

Quadro 1- Regiões do Estado do Rio Grande do Sul que são geograficamente idênticas de 1960 a 1996*.

(conclusão)

\begin{tabular}{|c|c|}
\hline Região 51 & $\begin{array}{l}\text { Frederico Westphalen. Caiçara. Palmitinho. Vicente Dutra. } \\
\text { Pinheirinho do Vale. Taquaruçu do Sul. Vista Alegre. }\end{array}$ \\
\hline Região 52 & $\begin{array}{l}\text { Seberi. Erval Seco. Palmeira das Missões. Tenente Portela. Rodeio } \\
\text { Bonito. Constantina. Liberato Salzano. Nonoai. Irai. Alpestre. } \\
\text { Planalto. Sarandi. Rondinha. Panambi. Condor. Santo Augusto. } \\
\text { Coronel Bicaco. Campo Novo. Ijuí. Ajuricaba. Augusto Pestana. } \\
\text { Cruz Alta. Santo Ângelo. Pejuçara. Ronda Alta. Braga. Redentora. } \\
\text { Miraguaí. Três de Maio. Independência. Boa Vista do Buricá. } \\
\text { Crissiumal. Humaitá. São Martinho. Fortaleza dos Valos. } \\
\text { Tupanciretã. Jóia. Salto do Jacuí. Espumoso. Sobradinho. Arroio } \\
\text { do Tigre. Ibarama. Segredo. Barra Funda. Boa Vista das Missões. } \\
\text { Cerro Grande. Jaboticaba. Lajeado do Bugre. Nova Boa Vista. } \\
\text { Novo Barreiro. Pinhal. Sagrada Família. Chapada. São José das } \\
\text { Missões. Alto Alegre. Campos Borges. Ibirubá. Quinze de } \\
\text { Novembro. Ametista do Sul. Engenho Velho. Dois Irmãos das } \\
\text { Missões. Gramado dos Loureiros. Novo Tiradentes. Rio dos } \\
\text { Índios. Três Palmeiras. Trindade do Sul. Alegria. Coronel Barros. } \\
\text { São Valério do Sul. Erechim. Barão do Cotegipe. Aratiba. São } \\
\text { Valentim. Itatiba do Sul. Jacutinga. Campinas do Sul. Mariano } \\
\text { Moro. Severiano de Almeida. Viadutos. Marcelino Ramos. Lagoa } \\
\text { Vermelha. Ibiraiaras. Barracão. São José do Ouro. Cacique Doble. } \\
\text { Machadinho. Maximiliano de Almeida. Paim Filho. Sananduva. } \\
\text { André da Rocha. Barra do Rio Azul. Carlos Gomes. Entre Rios do } \\
\text { Sul. Faxinalzinho. Ponte Preta. Três Arroios. Caseiros. Carazinho. } \\
\text { Colorado. Tapera. Santa Bárbara do Sul. Selbach. Coqueiros do } \\
\text { Sul. Santo Antônio do Planalto. Não-Me-Toque. Victor Graeff. } \\
\text { Passo Fundo. Ciríaco. David Canabarro. Sertão. Ibiaçá. Saldanha } \\
\text { Marinho. Lagoa dos Três Cantos. Água Santa. Tapejara. Charrua. } \\
\text { Getúlio Vargas. Erebango. Ipiranga do Sul. Estação. Coxilha. } \\
\text { Ernestina. Gentil. Marau. Camargo. Mato Castelhano. Muliterno. } \\
\text { Nicolau Vergueiro. Pontão. Santo Antônio do Palma. São } \\
\text { Domingos do Sul. Vanini. Vila Maria. Guaporé. Serafina Corrêa. }\end{array}$ \\
\hline
\end{tabular}


Casca. Dois Lajeados. Montauri. São Valentim do Sul. União da Serra. Santo Expedito do Sul. São João da Urtiga. Tupanci do Sul. São José do Inhacorá. Entre-Ijuís. Eugênio de Castro. São Luiz Gonzaga. Caibaté. Bossoroca. Santo Antônio das Missões. São Nicolau. Dezesseis de Novembro. Pirapó. São Miguel das Missões. Vitória das Missões. Barra do Guarita. Bom Progresso. Três Passos. Derrubadas. Doutor Maurício Cardoso. Sede Nova. Tiradentes do Sul. Vista Gaúcha. Erval Grande. Catuípe. Chiapeta. Inhacorá.

\begin{tabular}{|l|l|}
\hline Região 53 & $\begin{array}{l}\text { Santa Rosa. Campina das Missões. Giruá. Cândido Godói. Porto } \\
\text { Lucena. Porto Vera Cruz. Santo Cristo. Alecrim. Horizontina. }\end{array}$ \\
\hline Região 54 & Tucunduva. Novo Machado. Porto Mauá. Tuparendi \\
\hline Região 55 & Arroio Grande \\
\hline Região 56 & Herval \\
\hline Região 57 & Jaguarão \\
\hline Região 58 & Rio Grande \\
\hline Região 59 & Santa Vitória do Palmar \\
\hline Região 60 & Canguçu \\
\hline Região 61 & Pedro Osório \\
\hline Região 62 & Pelotas. Capão do Leão. Morro Redondo \\
\hline Região 63 & São Lourenço do Sul. \\
\hline Região 64 & Caçapava do Sul. Santana da Boa Vista. \\
\hline Região 65 & Encruzilhada do Sul. Dom Feliciano. São Jerônimo. Camaquã. \\
& $\begin{array}{l}\text { Arroio dos Ratos. Butiá. Charqueadas. Tapes. Arambaré. Cerro } \\
\text { Grande do Sul. Sentinela do Sul. Guaíba. Eldorado do Sul. Mariana } \\
\text { Pimentel. Barra do Ribeiro. Sertão Santana. Barão do Triunfo. } \\
\text { Minas do Leão. Cristal. Amaral Ferrador. }\end{array}$ \\
\hline Região 66 & Piratini \\
\hline Região 67 & Rosário do Sul \\
\hline Região 68 & Santana do Livramento \\
\hline Região 69 & Bagé. Candiota. Pinheiro Machado. Hulha Negra. \\
\hline Região 70 & Dom Pedrito \\
\hline Região 71 & Lavras do Sul \\
\hline
\end{tabular}


316 - Evolução Regional da Produtividade da Mão-de-Obra na Agropecuária Gaúcha: uma Aplicação da Matriz de Markov

\begin{tabular}{|l|l|} 
Região 72 & Itaqui \\
\hline Região 73 & Quarai \\
\hline Região 74 & São Francisco de Assis. Manoel Viana. Alegrete. \\
\hline Região 75 & Uruguaiana \\
\hline
\end{tabular}

Fonte: regiões definidas com base em histórico das emancipações municipais disponível na Fundação de Economia e Estatística (FEE) do Rio Grande do Sul.

*Nota: embora este estudo se refira ao período de 1975 a 1996, consideraram-se as regiões definidas em dois estudos de Stulp (2003) e que abrangiam o período de 1960 a 1996, visando aproveitar as informações sobre um conjunto de variáveis disponíveis naqueles estudos. 